\title{
Phylogenetic analysis of genotype VII of new castle disease virus in Indonesia
}

\author{
NLP Indi Dharmayanti*, Risza Hartawan, Dyah Ayu Hewajuli and Risa Indriani \\ Indonesian Research Center for Veterinary Science, JL RE Martadinata 30, Bogor 16114, West Java, Indonesia. \\ Received 02 January, 2014; Accepted 10 March, 2014
}

\begin{abstract}
Newcastle disease (ND) is a very contagious disease in chickens and turkeys and one of the most important diseases of poultry in the world. The infection causes sudden death with high mortality. In Indonesia, Newcastle disease in recent years showed symptoms slightly different from previous symptoms of this disease. NDV infection of genotipe VII has been reported to cause this outbreak in several commercial poultry farms in Indonesia. This study aimed to isolate and identify the recent ND virus and determine group of genotype of ND in Indonesia for the development of seed of ND vaccines expected to be more effective in the control of Newcastle disease in the field. The method used in this study includes the collection of samples from the field, ND virus isolation, RT-PCR and DNA sequencing of the F and HN genes of ND viruses. Our result showed that six isolates belong to genotype VII of ND viruses, one isolate belong to genotype VI and the other isolate belong to genotype I. The prediction of pathotypes of amino acids sequence on F gene of NDV indicated that seven isolates have motif R-R-R-K-R and R-R-Q-K-R which is a marker for pathotype for velogenic of ND viruses. The cleavage site of amino acid sequences from one isolate (RIVS isolate) has G-K-Q-G-R-L which is lentogenic pathotype of NDV. This study indicated that genotype VII viruses were predominant virus circulating in the field and we suggested the update of master seed vaccine of ND in Indonesia.
\end{abstract}

Key words: New castle disease (ND), genotype VII, phylogenetic analysis.

\section{INTRODUCTION}

As an OIE list $A$ categorized disease, the outbreak of Newcatle disease (ND) has severly affected poultry Industries world-wide causing massive economic repercussion. The distribution of this highly contagius and infectious disease has already widely spread across many regions of the world. The etiological agent belongs to virulent serotypes of avian paramixovirus type 1 (APV1) of the genus Avulavirus, subfamily Paramyxovirinae and family Paramyxoviridae (ICTV, 2005). At least ten serotypes of avian paramyxovirus (APV1-APV10) have been recognized up to date (Miller et al., 2010). The genome of this enveloped virus is nonsegmented, singlestranded, negative sense RNA with approximately 15 kilo base pair (kbp) for entire genome size. The genome encodes for at least six major proteins including nucleocapsid $(N)$, phosphoprotein $(P)$, matrix $(M)$, fusion $(F)$, hemagglutinin-neuraminidase $(\mathrm{HN})$ and large polymerase (L) (Krishnamurthy and Samal ,1998; De Leeuw and

${ }^{*}$ Corresponding author. E-mail: nlpdharmayanti@yahoo.com.

Author(s) agree that this article remain permanently open access under the terms of the Creative Commons Attribution License 4.0 International License 
Peeters, 1999). Two non-structural proteins ( $\mathrm{V}$ and $\mathrm{W}$ ) are expressed at transcription process of $\mathrm{P}$ gene (Peeters et al., 2004; Steward et al., 2003). Moreover, the $\mathrm{HN}$ and $\mathrm{F}$ proteins are acknowledged to play important role in the virulence characteristic (Huang et al., 2004). These two surface protein surfaces are involved in the attachment and membrane fusion in the initial infection on the host cells (de Leeuw and Peeters, 1999; Lamb and Kolakofsk, 1996).

Manifestation of the disease may vary from subclinical to severe or systemic infection with high mortality rate depending on the virulence of virus strain and the host state and susceptibility. Based on the clinical symptomps in chicken, the NDV are grouped into five pathotypes including viscerotropic velogenic, neurotropic velogenic, mesogenic, lentogenic respiratory and asymtomatic enteric (Alexander and Senne, 2008). The concern about ND infection in the poultry industry should not be oriented only to the pathogenic strains since the apathogenic strains may contribute to economic drawback as well. The avirulent strain of APV1 could result in decreased productivity of the infected farms such as drop of egg production or poor body weight performance (Aldous and Alexander, 2003; Leuck et al., 2004; Ojok and Brown, 1996). Farmer's ignorant on the significance of avirulent ND strain in poultry farms may lead to unexpected income loss.

Historically, the outbreak of ND infection in Indonesia has been isolated more than eighty years ago (Kranevald, 1926). Some Diseases Investigation Center in Indonesia reported the isolation of NDV from outbreak occuring in their areas. The ND infection has become endemic in most regions of the country causing significant economic losses even in in Indonesia. However, the ND outbreaks are properly controlled by implementing intensive vaccination program in the commercial poultry farms. Numerous type of vaccines are available from several commercial sources including live and killed vaccine which consist of the Lasota strain for either single application or combination with other poultry diseases vaccines. Despite the fact that ND infection is overshadowed by current Asian highly pathogenic avian influenza H5N1 outbreak even in Indonesia, the ND viruses still pose threat to the poultry industries by maintaining their evolution and spread in the farm environment. In Indonesia, failure of the protection of the current vaccination program against ND infection perhaps caused by the seed vaccine did not match with the field NDV, mutation, or introduction exotic strain. Lately, NDV infection of genotipe VII has been reported to cause disease outbreak in several commercial poultry farms in Indonesia. The objectives of this study were to characterized recently isolated ND viruses by molecular approach as well as to determine genotypic grouping of ND viruses in Indonesia in order to look for candidate of new master seed vaccine that more effectively control ND outbreak in the field.

\section{MATERIALS AND METHODS}

\section{Samples collection and screening for ND virus}

Field samplings were conducted in several commercial chicken farm in Sukabumi (West Java Province) and Tangerang (Banten Province). Both districts have experienced recurrent outbreak of ND because of high density of poultry population in these areas. Type of sample collected in the fieldwork is chicken sera and cloacal swab. A sterile cotton-tipped swab was used for sampling of cloacal swab. Subsequently, the swabs were stored in viral transport medium consisting of Dulbecco's modified eagle medium (DMEM) with addition of antibiotic and antifungi. The samples were immediately transported to the Virologi Laboratory, IRCVS, Bogor for further analyses. The presence of antibody against ND was examined in the serum samples by hemagglutination inhibition $(\mathrm{HI})$ test using OIE standard methodology.

\section{Isolation ND viruses}

Virus isolation was conducted by inoculating cloacal samples into specific pathogen free (SPF) of embryonated chicken eggs (9-11 days) only for ND positive sample by RT-PCR test. Briefly about $1000 \mu \mathrm{l}$ sample in transport medium was homogenized by vortexing and subsequently centrifuged with the speed of $2500-3000 \mathrm{rpm}$. Then, supernatant was inoculated into embryonated egg via allantoic cavity with 4 days observation for death of embryo. Subsequently, the allantoic fluid was harvested and screened for the virus presence by rapid agglutination test for $10 \%$ chicken red blood cells in the porcelain plate. The positive agglutinated allantoic fluid was retested again by RT-PCR for the confirmation of ND viruses. Furthermore, the ND virus isolates were kept in the freezer at $-20^{\circ} \mathrm{C}$ for further analyses.

\section{Sequencing of PCR products}

Molecular characterization of ND virus isolates were accomplised by sequencing the $\mathrm{F}$ and $\mathrm{HN}$ gene. Briefly, RNA of ND virus was isolated using Viral RNA minikit (Qiagen). Subsequently, the RTPCR test designed by Liu et al. (2008) was performed to amplify the $\mathrm{F}$ gene with size of product in about 535 base pairs (bp). Meanwhile, the amplification of $\mathrm{HN}$ gene was carried out using Peroulis-Kourtis et al. (2002) method to generate product with size of $320 \mathrm{bp}$. The RT-PCR for both genes was conducted using the Superscript III One Step RT-PCR system (Invitrogen).

The DNA products were separated by gel electrophoresis and visualized by UV transluminator. Furthermore, specific amplification products were purified using QIAquick Gel Purification System (Qiagen) and quantified using NanoDrop 1000 spectrophotometer (Thermo Fisher Scientific Inc.). The DNA sequencing was performed by BigDye Terminator Cycle v3.1 Cycle Sequencing Kit (Applied Biosystem) in Genetyx Analyzer 3130 machine (Applied Biosystems, USA).

\section{Phylogenetic analysis and predicted amino acid of cleavage} site

The results of nucleotide sequence were verified and edited using Bioedit version 8 (http://www.mbio.ncsu.edu/BioEdit). The sequences of the $\mathrm{F}$ and $\mathrm{HN}$ gene were compiled and compared with the ND nucleotide sequece database in the genbank NCBI. Nucleotide analysis, prediction of amino acid sequences and multiple sequence alignment was done with Clustal W (BioEdit 8) and MEGA 5.2. Phylogenetic tree analyses for genotyping were generated by neighbor-joining bootstrap analysis (1,000 replicates) using the 
Table 1. Field samples for indentification of ND viruses using RT-PCR.

\begin{tabular}{lcccll}
\hline District/province & Total farm & Total samples & Positive by (RT-PCR - F gene) & Virus isolation & Remark \\
\hline Sukabumi & 16 & 171 & 22 & Negative & No clinical signs \\
Tangerang & 7 & 73 & 36 & Negative & No clinical signs \\
East java & 1 & 5 & 1 & Positive & High mortality \\
West java & 1 & 5 & 1 & Positive & High mortality tinggi \\
\hline
\end{tabular}

Table 2. Historical isolates of ND in Indonesia.

\begin{tabular}{lll}
\hline Name of virus & Species & Area \\
\hline I-337 & Chicken & West Java \\
I-14 & Chicken & West Java \\
I-171 & Chicken & East Java \\
I-237 & Chicken & Kupang, NTT \\
I-53 & Chicken & West Java \\
RIVS & Chicken & No data \\
\hline
\end{tabular}

Tamura-Nei algorithm in MEGA version 5.2 software (http://www.megasoftware.net).

\section{RESULTS}

\section{Identification of NDV}

The samples were collected from commercial layer farms in two districts, that is, in Sukabumi and Tangerang. In addition, several samples were also obtained from broiler farms in East Java Province. Hemagglutination inhibition test revealed that all the poultry farms where vaccination was done showed various value of antibody titers in the range of between 5-11 log2 (data not shown). Most of chicken farms may have problem with NDV even though vaccination is routinely implemented. The RT-PCR assay identified presence of NDV in numerous cloacal swab samples (Table 1); however, only two isolates viruses of ND can be grown in embryonated eggs of SPF chicken. In this study, we did further analyze DNA sequencing for the new isolated viruses, that is, GTT/11 and SME/13 for as well as six other NDV isolates from our laboratory, namely I-337, I-14, I-171, I-1237, I-53 and RIVS (Table 2). The DNA sequencing was succesfully accomplished from the RT-PCR product of $\mathrm{F}$ and $\mathrm{HN}$ gene in about 535 base and $320 \mathrm{bp}$, respectively.

\section{Phylogenetic analysis}

The phylogenetic tree analysis of $\mathrm{F}$ gene demonstrated that most of ND isolates used in this study belong to genotype VII. The newly isolated NDV, that is, GTT/11 and SME/13 are classified in genotype IV that have close relationship with the other Indonesian GVII viruses isolated in 2005. Despite the fact that the other four historical isolates (I-337, I-14, I-171 and I-1237) also belong to genotype VII, they showed more similar relationship with the other GVII viruses isolated in 1990 (Figure 1). Moreover, the I-53 and RIVS are categorised as genotypes I and $\mathrm{VI}$, respectively. Concurrently, the phylogenetic tree analysis of $\mathrm{HN}$ gene showed that GTT/11 and SME/13 isolates have close genetic proxi-mity with other Indonesian ND viruses isolated in 2010 (Figure 2).

\section{Proteolytic cleavage site of F0 protein}

The genetic analyses of amino acid sequences of the NDV isolates were compared with the NDV database from GenBank (NCBI). Based pathotypes prediction on cleavage site of fussion protein, six isolates (GTT/11, I337, I-171, I-14, I-237) have motif of amino acid R-R-R-K$\mathrm{R}$ and two other isolates (I-53 and SME/13) exhibit motif of R-R-Q-K-R. These amino acids sequence motifs are marker for velogenic or mesogenic pathotypes. Conversely, the amino acid motif of RIVS isolate is G-KQ-G-R-L, which is marker for lentogenic pathotype of NDV (Figure 3).

\section{DISCUSSION}

Amino acid sequence of cleavage site on $\mathrm{F}$ gene can be used to predicted pathotypes of NDV. This sequence analysis of the $\mathrm{F}$ protein can be done instead of conventional methods such as mean death time (MDT) and intracerebral pathogenicy index test (ICPI) (Panda et al., 2009). Pathotype and virulence of NDV can be predicted from amino acid sequence on cleavage site of F0 protein after post-translational modification. The amino acid sequence at the $\mathrm{F}$ protein cleavage site is different among most lentogenic, mesogenic and velogenic NDV strains (Millar et al., 1988). Mostly, virulent strains comprise motif ${ }^{112} \mathrm{R} / \mathrm{K}-\mathrm{R}-\mathrm{Q}-\mathrm{K} / \mathrm{R}-\mathrm{R}^{116}$ at the C-terminus of the F2 protein and phenylalanine $(\mathrm{F})$ at residue 117 at $\mathrm{N}$-terminus of the $\mathrm{F} 1$ protein. Meanwhile, the low virulent strains retain motif ${ }^{112} \mathrm{G} / \mathrm{E}-\mathrm{K} / \mathrm{R}-\mathrm{Q}-\mathrm{G} / \mathrm{E}-\mathrm{R}^{116}$ in the same region and leucine (L) at the same position (Collins et al., 1993; Panda et al., 2004).

In our study, seven isolates have multibasic amino acids sequence on cleavage site that indicated the velogenic and mesogenic NDV strains (Seal et al., 1995). On the other hand, one isolate is classified as lentogenic strain because it has monobasic amino acid motif in 


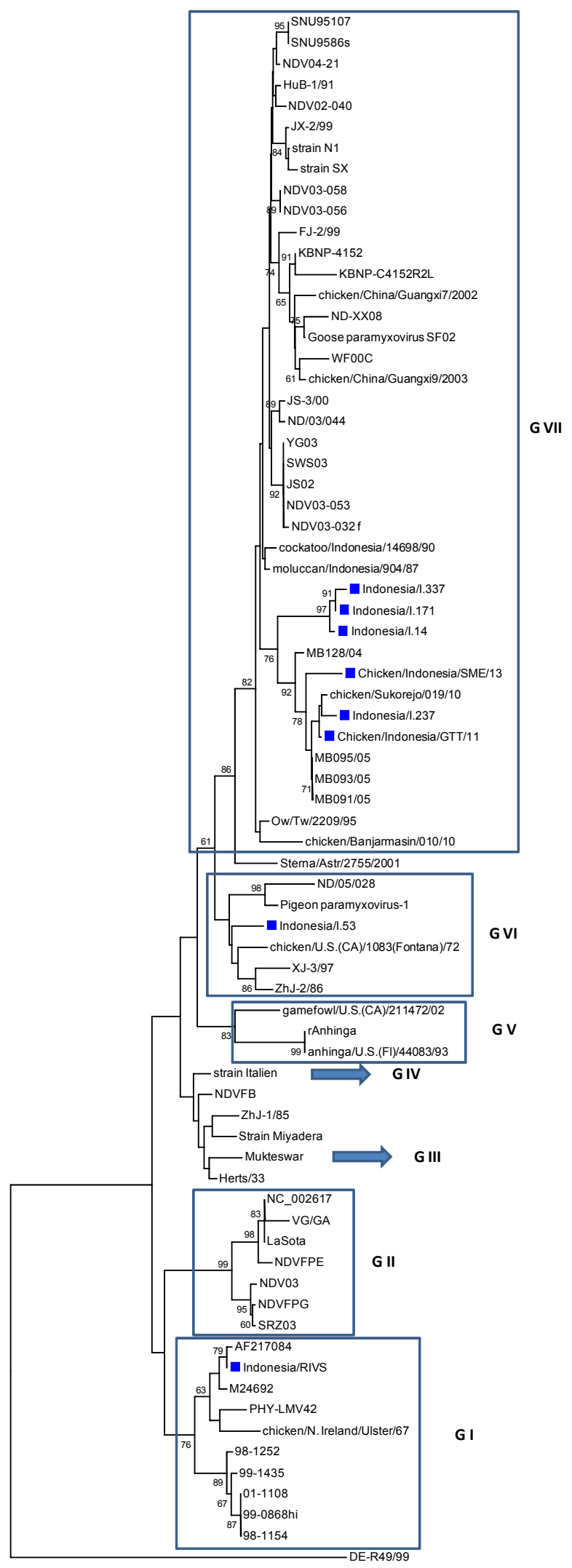

Figure 1. Phylofenetic tree of partial of Fussion (F) gene of ND viruses. Indonesian viruses used in this study are shown in blue color. The region of the fussion from 198-450 was analyzed using MEGA version 5.2. A neighbor-joining bootstrap analysis (1.000 replicates) using the Kimura-Nei model. 


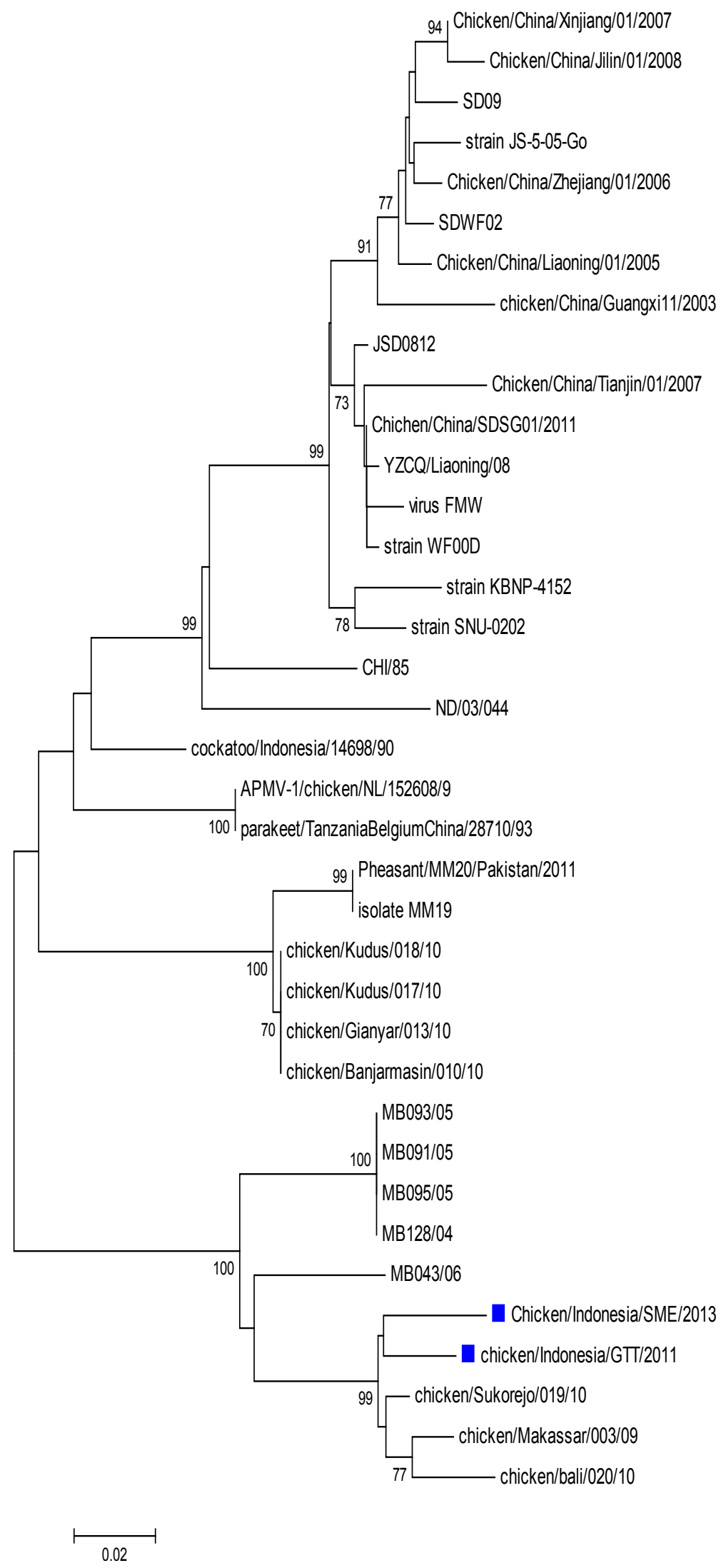

Figure 2. Phylogenetic tree of hemagglutinin-neuraminidase $(\mathrm{HN})$ gene of ND viruses. Viruses used in this study are shown in blue color. 
LaSota

DE-R49/99

chicken/Sukorejo/019/10

MB095/05

MB091/05

moluccan/Indonesia/904/87

chicken/Banjarmasin/010/10

Indonesia/I. 337

Indonesia/RIVS

Indonesia/I.237

Indonesia/I.171

Indonesia/I . 53

Indonesia/I 14

Chicken/Indonesia/GTT/2011

Chicken/Indonesia/SME/2013

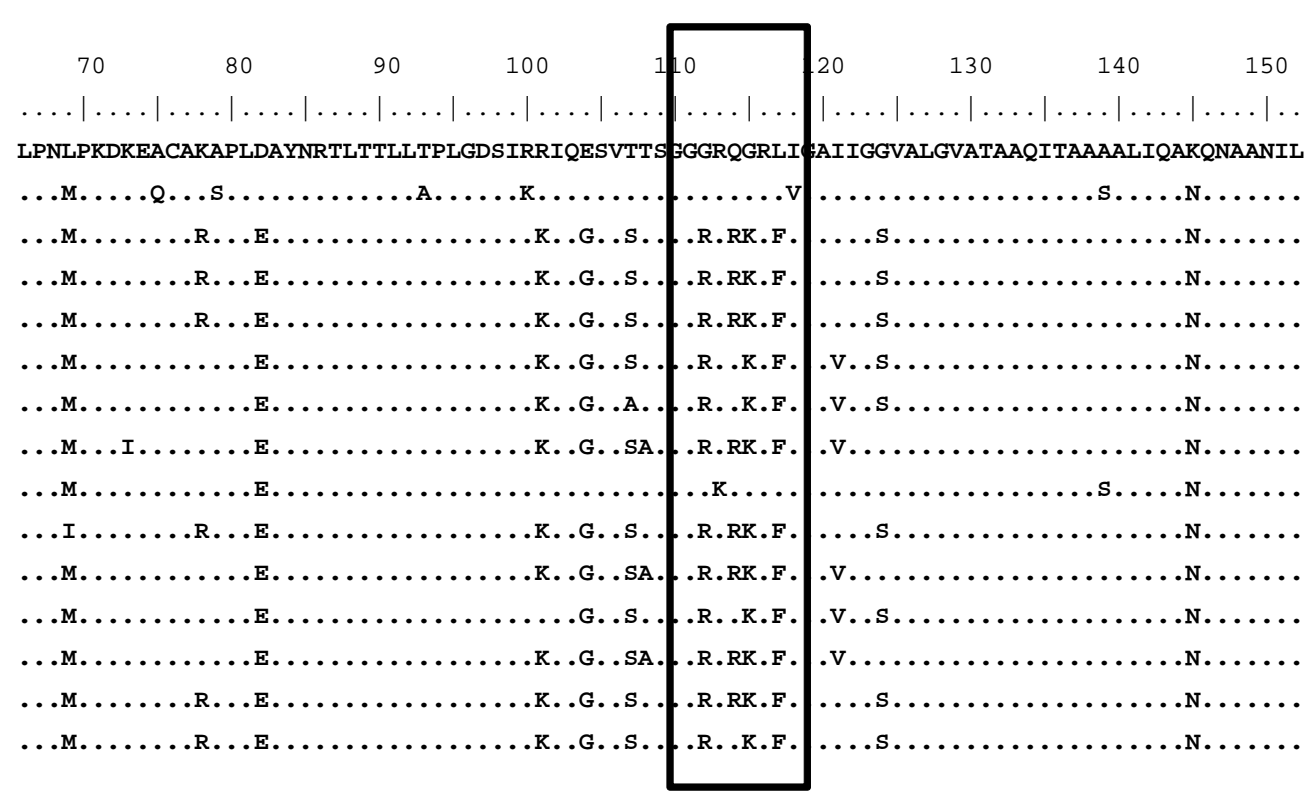

Figure 3. Cleavage site of amino acid sequences prediction on F gene of ND viruses as shown in the black color box.

cleavage site on F protein (Seal et al., 1995).

Based on phylogenetics, ND viruses are classified into two classes, namely Class I and II. Class I of ND viruses have genome sizes typically 15198 nucleotides which were isolated from waterfowl and domestic poultry and usually are avirulent. Class II of ND viruses are a group of viruses most virulent and avirulent viruses with some genotypes I- IV found prior to 1960 with the genome size of 15186, while genotype V-VIII, a new strain that was isolated after 1960 with a genome size of 15192 nt. genotype VII and VIII are new genotypes found after 1980 that caused a pandemic in Europe, the Far East and South Africa (Czegledi et al., 2006; Herczeg et al., 1999; Ke et al., 2001; Lomniczi et al., 1998; Abolnik et al., 2004; Liu et al., 2007). The results of our study showed that the ND virus used in this study was six isolates belonging to genotype VII, one virus was genotype 1 and other virus are genotype VI. The genetic analysis showed that genotype VII is the dominant group of viruses circulating in Indonesia after 2005, almost Indonesian ND viruses isolated after 1990 also belong to genotype VII. This study identified little differences on the amino acids sequences among viruses in the group of genotype VII. The isolates of ND that we isolated from this study (GTT/11 and SME/13) have dissimilar amino acid sequences of cleavage site on $F$ gene. The GTT/11 isolate have typical velogenic pathotype of NDV. Regardless of the SME/13 isolate based on phylogenetic tree, it belong to genotype VII, but the amino acid sequence of cleavage site have similar motif with I-53. Our result revealed that the $\mathrm{I}-53$ isolate belong to genotype VI, and based on Parade (1987) study, the I53 isolate was a mesogenic group of viruses. The isolate of SME/13 was collected from outbreak of ND with high mortality in commercial chicken farm. The recent ND viruses were estimated to be the cause of problem in poultry, so it takes the suitability of the seed vaccine viruses circulating in the field. Our analysis shows that the viruses circulating in Indonesia are viruses that have a high similarity with GTT/11 and SME/13, no new findings on virus which belong to genotypes I and others, because genotype VII is a virus that predominate NDV currently circulating in the field.

There are many kinds of vaccine available in Indonesia. They are used as part of government policy to control ND in Indonesia. The vaccines are imported or produced locally using overseases strains under the government authority. The seed of strains used for local production are still imported strains such as B1, LaSota, F, Komarov (Parede, 1987). Recently, some local vaccine factories used the local strain of NDV to control ND in Indonesia. For years, most of commercial farms in Indonesia have practiced intensive ND vaccinations using both live and inactivated vaccines. In addition, LaSota strain belonging to genotype II is widely used as live vaccine in the field. However, the epidemiological circumstances of ND have been changed by reports of ND outbreaks in the vaccinated chicken flocks. The emergence of new genotypes and antigenic variants of ND infection arose by introduction of the new circulating ND viruses of genotype VII in the farm environment. Despite the fact that significant genotype dissimilarity between seed vaccine and newly identified viruses have been identified, the traditional vaccine of LaSota still could provide certain protection against new genotype VII ND infection because the antigenicity attributes have not changed dra- 
matically. However, the high level $\mathrm{HI}$ antibody value of flock immunity (up to 8log2) maybe required to protect against this new genotype (Liu et al., 2008; Panshin et al., 2002; Yu et al., 2001).

Developing ND seed vaccine in accordance with the field virus circulation should be done to control and reduce the economic impact caused by this disease, so based on this study, it is recommended that the ND virus genotype VII should be used as a new master seed which is expected to induce antibodies and provide good protection against the new field strain of ND virus in Indonesia.

\section{Conflict of Interests}

The author(s) have not declared any conflict of interests.

\section{ACKNOWLEDGEMENTS}

We thank to Nana Suryana and Teguh Suyanto for their technical support, assistance and District Livestock Servises in Tangerang, Sukabumi and East Java for the field support. This study was supported by DIPA Grant from The Indonesian Agency of Agricultural Research and Development (IAARC), Ministry of Agriculture

\section{REFERENCES}

Abolnik C, Horner RF, Bisschop SPR, Parker ME, Romito M, Viljoen GJ (2004). A phylogenetic study of South African Newcastle disease virus strains isolated between 1990 and 2002 suggests epidemiological origins in the Far East. Arch. Virol. 149:603-619.

Aldous EW, Alexander DJ (2001). Detection and differentiation of Newcastle disease virus (Avian paramyxovirus type 1). Avian Pathol. $30: 117-128$

Czeglédi A, Ujvari D, Somogyia E, Wehmanna E, Werner O, Lomniczi B (2006). Third genome size category of avian paramyxovirus serotype 1 (Newcastle disease virus) and evolutionary implications. Virus Res. 120:36-48

de Leeuw O, Peeters B (1999). Complete nucleotide sequence of Newcastle disease virus: evidence for the existence of a new genus within the subfamily Paramyxovirinae. J. Gen. Virol. 80:131-136.

Herczeg J, Wehmann E, Bragg RR, Travassos Dias PM, Hadjiev G, Werner O, Lomniczi B (1999). Two novel genetic groups (VIlb and VIII) responsible for recent Newcastle disease outbreaks in Southern Africa, one (VIlb) of which reached Southern Europe. Arch. Virol. 144: 2087-2099.

Huang Z, Panda A, Elankumaran S, Govindarajan D, Rockeman DD, Samal SK (2004). The Hemaglutinin-neuraminidase protein of Newcastle disease virus determines tropism and virulence. J. Virol. 78: 4176-4184.

ICTV (2005). Virus Taxonomy: Classification and Nomenclature of Viruses: Eighth Report of the International Committee on the Taxonomy of Viruses. Elsiever Academic Press, San Diego.

Ke MG, Liu JH, Lin YMH, Chen J, Tsai SS, Chang CP (2001). Molecular characterization of Newcastle disease viruses isolated from recent outbreaks in Taiwan. J. Virol. Methods 97:1-11.

Kranevald FC (1926). N.I.Bladen v.Dierg. 38. ed.5
Krishnamurthy S, Samal SK (1998). Nucleutide sequences of the trailer, nucleocapsid protein gene and intergenic regions of Newcastle disease virus strain Beaudette $\mathrm{C}$ and completion of the entire genome sequence. J. Gen. Virol. 79: 2419-2424.

Lamb RA, Kolakofsky D (1996). Paramyxoviridae: The viruses and their replication. Fields Virology Philadelphia. Lippincott-RavenFields BN, Knipe DM, Howley PM. 3 : 1177-1203

Liu H, Wang Z, Wu Y, Sun C, Zheng D, Xu T, Li J (2008). Molecular characterization and phylogenetic analysis of new Newcastle disease virus isolates from the mainland of China. Res. Vet. Sci. 85:612-616.

Liu H, Wang Z, Wu Y, Zheng D, Sun C, Bi D, Zuo Y, Xu T (2007). Molecular epidemiological analysis of Newcastle disease virus isolated in China in 2005. J. Virol. Methods 140: 206-211.

Lomniczi B, Wehmann E, Herczeg J, Ballagi-Pordany A, Kaleta EF, Werner O, Meulemans G, Jorgensen PH, Mante AP, Gielkens AL, Capua I, Damoser J (1998). Newcastle disease outbreaks in recent years in Western Europe were caused by an old $(\mathrm{VI})$ and a novel genotype (VII). Arch. Virol. 143:49-64.

Millar NS, Chambers P, Emmerson PT (1988). Nucleotide sequence of the fusion and hemagglutinin-neuraminidase glycoprotein genes of Newcastle disease virus, strain Ulster: molecular basis for variations in pathogenicity between strains. J. Gen. Virol. 69: 613-20.

Ojok L, Brown C (1996). An immunohistochemical study of the pathogenesis of virulent viscerotropic Newcastel disease in chickens. J. Comp. Pathol. 115: 221-227.

Panshin, A, Shihmanter E, Weisman Y, Orvell C, Lipkind M (2002). Antigenic heterogeneity amongst the field isolates of Newcastle disease virus (NDV) in relation to the vaccine strain. Part II: studies on viruses isolated from domestic birds in Israel. Comp. Immunol. Microbiol. Infect Dis. 25 (3) : 173-185.

Parede L (1987). Experimental studies on pathogenesis of Newcastle Disease in vaccination and unvaccinated birds. Graduate School of Tropical Veterinary Science. The James Cook University of North Queensland. 42-44

Peeters B, Verbruggen P, Nellisen F De Leeuw O (2004). The P gene of the Newcastle disease virus does not encode an accessory $X$ protein. J. Gen. Virol. 5: 2375-2378.

Peroulis-Kourtis I, O'Riley K, Grix D, Condron RJ, Ainsworth (2002). Molecular characterisation of Victorian Newcastle disease virus isolates from 1976 to 1999. Aust. Vet. J. 80:422-424.

Seal BS, King DJ, Bennett JB (1995). Characterization of Newcastle disease virus isolates by RT-PCR coupled to direct nucleotide sequencing and development of sequence database for pathotype prediction and molecular epidemiologic analysis. J. Clin. Microbiol. 33: $2624-30$

Steward M, Vipond IB, Millar NS, Emmerson PT (1993). RNA editing in Newcastle disease virus. J. Gen. Virol. 74: 2539-2547.

Yu L, Wang Z, Jiang Y, Chang L, Kwang J (2001). Characterization of newly emerging Newcastle disease virus isolates from the People's Republic of China and Taiwan. J. Clin. Microbiol. 39 (10) : 35123519. 